\title{
Análise temporal e controle da mancha-anular e do ácaro vetor do Coffee ringspot virus
}

\author{
João Eduardo Melo de Almeida(1), Arnaldi Eiki Mori(1), Edson Ampélio Pozza(1), \\ Paulo Rebelles Reis ${ }^{(2)}$ e Antonia dos Reis Figueira( ${ }^{(1)}$ \\ (1) Universidade Federal de Lavras, Departamento de Fitopatologia, Caixa Postal 3037, CEP $37200-000$ Lavras, MG. \\ E-mail: joaomeloalmeida@gmail.com, arnaldi_mori@hotmail.com, pozza@dfp.ufla.br, antonia@dfp.ufla.br (2)Empresa de \\ Pesquisa Agropecuária de Minas Gerais, Centro Tecnológico do Sul de Minas, Caixa Postal 176, CEP $37200-000$ Lavras, MG. \\ E-mail: paulo.rebelles@epamig.ufla.br
}

Resumo - O objetivo deste trabalho foi avaliar a flutuação populacional do ácaro Brevipalpus phoenicis, vetor do Coffee ringspot virus (CoRSV) - agente causal da mancha-anular do cafeeiro -, bem como a sua distribuição em plantas de café e o efeito de acaricidas no seu controle em lavouras cafeeiras. O experimento foi realizado no Município de Coromandel, na região do Alto do Paranaíba, MG, durante dois anos. No segundo ano, avaliou-se o progresso da doença, e determinou-se a relação entre o crescimento populacional do ácaro e a incidência da doença. Observou-se que a mancha-anular e o ácaro ocorreram durante todo o ano, com maiores populações e incidência da doença nos meses com menores índices pluviais e temperaturas amenas. As análises de Pearson mostraram correlação negativa entre os parâmetros climáticos e a população do ácaro. Na análise da incidência da doença em diferentes épocas, verificou-se correlação positiva entre a primeira avaliação e as avaliações subsequentes. Quanto à distribuição espacial, foi observada a presença do ácaro em toda a planta; porém, as folhas são preferidas pelos adultos, enquanto os frutos são preferidos para oviposição. Os acaricidas são eficientes para manter a população do ácaro em baixos níveis, com consequente diminuição da incidência da doença.

Termos para indexação: Brevipalpus phoenicis, acaricidas, análise de correlação, vetor.

\section{Temporal analysis and control of the ringspot disease and mite vector of Coffee ringspot virus}

\begin{abstract}
The objective of this work was to evaluate the population fluctuation of the mite Brevipalpus phoenicis, vector of the Coffee ringspot virus (CoRSV) - the causal agent of the coffee ringspot disease -, as well as its distribution in coffee plants, and the effect of acaricides in its control in coffee crops. The experiment was carried out at the municipality of Coromandel, in the region of Alto do Paranaíba, MG, Brazil, during two years. In the second year, the progress of the disease was evaluated, and the relationship between the mite population and disease incidence was determined. Ringspot disease and mites were detected throughout the year, with larger populations and disease incidence in the months with lower rainfall and mild temperatures. Pearson analyses showed negative correlation between the climatic parameters and the mite population. In the analysis of the disease incidence in different periods, a positive correlation was found among the first and subsequent evaluations. Regarding spatial distribution, mite presence was observed in the whole plant; however, leaves are preferred by the adults, whereas the fruit are preferred for oviposition. The acaricides are effective in keeping the mite population at low levels, with consequent reduction of disease incidence.
\end{abstract}

Index terms: Brevipalpus phoenicis, acaricides, correlation analysis, vector.

\section{Introdução}

A cafeicultura é uma das principais atividades do setor agrícola brasileiro, por se tratar de grande geradora de empregos e de renda para o país. Em 2011, a produção mundial de café (Coffea arabica L.) situouse em torno de 130 milhões de sacas de $60 \mathrm{~kg}$, dos quais 43 milhões foram produzidos no Brasil. A produção brasileira concentra-se no Sudeste, com destaque para Minas Gerais, que produzirá, na safra de 2012/2013, cerca de 26 milhões de sacas, ou seja, mais de 52\% da safra nacional prevista para este ano, que atingirá em torno de 68 milhões de sacas. Essa será a maior safra já produzida no país, o que supera o recorde de $2002 / 2003$, que foi de 48,48 milhões de toneladas (Companhia Nacional do Abastecimento, 2012). 
As doenças no cafeeiro, causadas por fungos, bactérias, nematoides e vírus, são consideradas de grande importância, por serem capazes de causar perdas significativas na produção. Até o momento, uma única doença virótica foi detectada no cafeeiro, conhecida popularmente como mancha-anular do cafeeiro (MAC). Trata-se de uma doença cujo agente etiológico é o Coffee ringspot virus (CoRSV), descrito por Bittancourt (1938), e que tem como vetor o ácaro Brevipalpus phoenicis (Geijskes, 1939) (Acari: Tenuipalpidae), denominado vulgarmente de ácaro da mancha-anular, ácaro-plano ou ácaro-da-leprose.

Os sintomas da mancha-anular podem ser observados nas folhas, nos frutos e nos ramos das plantas. Nas folhas, os sintomas são detectados na nervura central e desenvolvem-se em direção ao pecíolo, o que causa a sua queda precoce, sobretudo no interior da copa. Quando em alta intensidade, essa queda reduz a área foliar da planta, dando origem ao sintoma popularmente conhecido como planta oca, o que leva a perdas significativas. Alguns frutos com alta incidência de sintomas do CoRSV ficam suscetíveis à infecção por fungos oportunistas, principalmente os necrotróficos, 0 que causa a sua queda precoce. Investigações recentes também têm mostrado que o CoRSV pode afetar a qualidade da bebida do café (Reis \& Chagas, 2001; Boari et al., 2006; Reis et al., 2010).

Desde a sua descoberta em 1938, a mancha-anular do cafeeiro ficou esquecida, em razão da sua baixa incidência e severidade nos campos onde foi detectada. No entanto, a partir de 1995, começou a chamar a atenção dos produtores e técnicos, por ter causado grande desfolha e, em alguns casos, queda de frutos em diversas lavouras localizadas no Alto Paranaíba (Coromandel, Patrocínio e Monte Carmelo), no sul de Minas Gerais (Boa Esperança, Campos Gerais e Três Pontas), no triângulo mineiro e em alguns municípios de São Paulo, na região da Alta Mogiana (Franca e Pedregulho) (Chagas, 1973, 1978; Reis \& Zacarias et al., 2007; Figueira, 2008; Reis et al., 2008).

Esse aumento na incidência e na severidade da mancha-anular, nos cafezais brasileiros, pode estar relacionado a diversos fatores, principalmente ao aumento da população do vetor e à expansão da cultura para áreas com microclimas favoráveis à doença. Nas últimas décadas, novas fronteiras agrícolas vêm sendo exploradas na cafeicultura, incluindo regiões com condições climáticas adversas e com solos pobres, carentes de correções e adubações intensivas, como as áreas de Cerrado. Apesar de essas áreas serem cultivadas com alto nível tecnológico, com uso de mecanização e irrigação, elas apresentam alta predisposição a epidemias. Em geral, nessas regiões, a temperatura média ao longo do ano varia entre $20 \mathrm{e}$ $28^{\circ} \mathrm{C}$, e pode chegar a $40^{\circ} \mathrm{C}$ em algumas localidades, o que pode favorecer a ocorrência de doenças e pragas.

Além da temperatura, a pluviosidade mal distribuída e o uso intensivo de agroquímicos podem ser considerados fatores decisivos, capazes de influenciar a densidade populacional do ácaro vetor e a taxa de progresso da doença, com consequente aumento na disseminação e na severidade da mancha-anular. Diversos autores observaram que a temperatura, o estresse hídrico e a má distribuição das chuvas podem contribuir para o aumento populacional do ácaro B. phoenicis (Reis et al., 2000; Franco et al., 2008) e que temperaturas mais altas, em torno de $28^{\circ} \mathrm{C}$, favorecem a multiplicação do CoRSV na planta hospedeira (Figueira, 2008). Finalmente, o uso repetido de acaricidas com o mesmo modo de ação também pode levar ao desenvolvimento de resistência nos ácaros, o que torna o seu controle ineficiente (Franco et al., 2008; Fernandes et al., 2010).

O padrão de ocorrência das doenças causadas por vírus, nos campos de produção, não é um processo estático, pois existe variabilidade na distribuição da doença no espaço e no tempo. Além disso, os patossistemas viróticos são complexos e caracterizados pelo patógeno viral, pela planta hospedeira e pelo vetor, quando existente, e por fatores climáticos (Harisson, 1983). Outros fatores, como o inóculo inicial da doença, a latência do vírus na planta, a severidade da doença, a idade em que a planta foi infectada e particularidades ligadas ao vetor - como nível populacional, quantidade de partícula viral adquirida e mecanismo de transmissão -, também devem ser considerados. $\mathrm{O}$ conhecimento desse conjunto de dados é fundamental para o embasamento de medidas voltadas para o manejo da doença no campo (Kitajima \& Costa, 1972; Madden et al., 2007; Jeger et al., 2009).

Pesquisas realizadas para controlar a mancha-anular têm sido direcionadas ao controle do vetor $B$. phoenicis (Reis et al., 1998, 1999, 2000, 2005; Fernandes et al., 2010). Entretanto, estudos sobre o patógeno ainda são escassos. 
O objetivo deste trabalho foi avaliar a flutuação populacional do ácaro Brevipalpus phoenicis, vetor do Coffee ringspot virus (CoRSV) - agente causal da mancha-anular do cafeeiro -, bem como a sua distribuição em plantas de café e o efeito de acaricidas no seu controle em lavouras cafeeiras.

\section{Material e Métodos}

O experimento foi conduzido durante dois anos em uma fazenda localizada no Município de Coromandel, na região do Alto Paranaíba, MG $\left(18^{\circ} 28^{\prime} 25^{\prime \prime} \mathrm{S}\right.$ e $47^{\circ} 12^{\prime} 47^{\prime \prime} \mathrm{W}$, a $950 \mathrm{~m}$ de altitude), com precipitação e temperatura média anual de $1.300 \mathrm{~mm} \mathrm{e}$ $24^{\circ} \mathrm{C}$, respectivamente. A cultivar utilizada foi a Catuaí-Vermelha, plantada em Latosolo Vermelho-Amarelo distrófico, com espaçamento 4,0x0,5 m, em duas áreas: Área 1, com oito anos de idade; e Área 2, com 15 anos na ocasião da implantação do experimento, distantes cerca de $300 \mathrm{~m}$ uma da outra. A coleta das amostras foi realizada aleatoriamente em 30 plantas, a cada 30 dias, durante dois anos. Em cada amostragem, foram retiradas cinco folhas e um ramo de $20 \mathrm{~cm}$, todos no terço inferior e interno de cada planta.

$\mathrm{Na}$ época da frutificação/maturação dos frutos, de março a junho, também foram coletados dez frutos de cada planta. $\mathrm{O}$ material coletado (folhas, ramos e frutos) de cada planta foi acondicionado dentro de caixas térmicas, forradas com gelo para manter a temperatura abaixo de $10^{\circ} \mathrm{C}$, e, em seguida, foi levado para o laboratório da Universidade Federal de Lavras, $\mathrm{MG}$, onde foram realizadas as contagens do número de ácaros, em todos os estádios de desenvolvimento, com auxílio de microscópio estereoscópico Nikon, com aumento de 40 vezes. O número de ácaros nos estádios de ninfas, larvas e adultos foi somado e denominado como "Ácaros". Para avaliar a doença, foi considerada a incidência nas folhas, tendo-se utilizado escala diagramática (Mori, 2003). Com os dados coletados, foi possível analisar a flutuação populacional, a distribuição espacial de $B$. phoenicis e o progresso da doença.

Por meio da análise de correlação de Pearson, foram verificadas as possíveis associações entre a população de ácaros e a incidência da doença. Analisou-se a correlação entre a quantificação da presença de ácaros na primeira avaliação e a incidência da mancha-anular aos 30, 60 e 90 dias após a avaliação do vetor. A correlação entre a população de ácaros, as variáveis climáticas - precipitação e temperatura média mensal - e a incidência da doença em determinada data também foi investigada, com avaliações aos 30,60 e 90 dias anteriores (D). Essas análises foram realizadas no programa SAS (SAS Institute, 2009), a 5\% de probabilidade.

O experimento com acaricidas foi realizado nas duas áreas experimentais. Utilizou-se delineamento experimental de blocos inteiramente casualizados, com dez plantas por parcela, três tratamentos e três repetições. Os tratamentos foram constituídos pela testemunha sem tratamento e por pulverizações com os acaricidas Dicofol 480 EC $(75 \mathrm{~mL}$ por $100 \mathrm{~L}$ de água) e Cihexatina $500 \mathrm{SC}$ (50 g por $100 \mathrm{~L}$ de água), a cada 90 dias. Para isso, utilizou-se atomizador costal motorizado, modelo L-80 (Cifarelli, Voghera, Itália), com capacidade de $17 \mathrm{~L}$, regulado para vazão de $1.000 \mathrm{~L} \mathrm{ha}^{-1} \mathrm{e}$ manejado para atingir todas as partes das plantas, inclusive as internas, nos ramos onde os ácaros podem se esconder debaixo da casca. As avaliações foram realizadas nas seis plantas centrais das parcelas, para anular o efeito de bordadura. A amostragem de ramos para a avaliação dos ácaros e da doença foi idêntica à realizada no experimento anterior. A análise estatística foi realizada no programa SISVAR (Ferreira, 2008), e as variáveis significativas pelo teste F foram analisadas pelo teste de Scott-Knott, a 5\% de probabilidade.

\section{Resultados e Discussão}

No período em que o experimento foi realizado, os totais mensais de precipitação pluvial variaram entre 0 e $267 \mathrm{~mm}$, e a temperatura media mensal ficou entre 18 e $25^{\circ} \mathrm{C}$. Tanto na Área 1 quanto na Área 2, foram verificados picos populacionais do ácaro de março a setembro, além de menores índices de outubro a fevereiro, quando houve maior precipitação pluvial e altas temperaturas. Embora na Área 2, no primeiro ano de avaliação, tenha ocorrido pico populacional atípico em dezembro (Figura 1), as maiores populações foram registradas nos meses de menores índices pluviais e temperaturas mais amenas. $\mathrm{Na}$ Área 1, houve correlação negativa entre a população de ácaros e a temperatura (TP) $(-0,37)$ e a população de ácaros e a pluviosidade (IP) $(-0,36)$, com 
correlação positiva, mas não significativa, na Área 2 $(\mathrm{TP}=0,15 ; \mathrm{IP}=0,18)$. Outros trabalhos realizados no sul de Minas Gerais também registraram menor população de $B$. phoenicis nos períodos de outubronovembro e fevereiro-março, que foram mais chuvosos e apresentaram temperaturas mais elevadas, bem como maior população no período de abril a setembro, com temperaturas mais amenas (Reis et al., 2008; Pedro Neto et al., 2010).

Além da temperatura e da pluviosidade, outro fator que influencia o desenvolvimento do ácaro é o estádio fenológico das plantas. De março a setembro, quando foram encontradas as maiores populações de B. phoenicis, ocorre o período reprodutivo do cafeeiro, no qual as plantas estão bem enfolhadas, com carga pendente. Em citros, Czermainski et al. (2007) também verificaram que, para o bom crescimento da população de $B$. phoenicis, tanto as condições climáticas quanto o estádio fenológico da planta devem ser favoráveis. Estes autores observaram que as maiores populações do vetor ocorreram nos meses secos e frios do ano, quando as plantas estavam em período reprodutivo, com carga pendente de frutos, e que houve maior preferência do vetor nessa fase da planta.

Os maiores índices da doença, em ambas as áreas, foram registrados no período de menor intensidade pluvial, de março a setembro, quando também foram observados os maiores índices populacionais de ácaros (Figura 2). Não houve correlação significativa entre a população do ácaro e a intensidade da doença, mas houve correlação positiva significativa na Área $1(0,57)$ e na Área $2(0,59)$, entre a intensidade da doença na

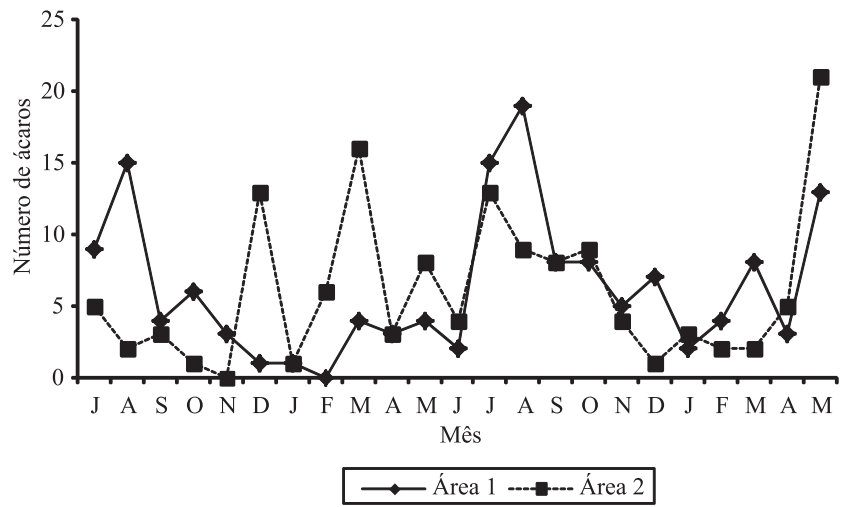

Figura 1. Flutuação populacional do ácaro (Brevipalpus phoenicis) durante dois anos de avaliação em duas áreas experimentais de cafeeiro (Coffea arabica), em Coromandel, MG. primeira avaliação e a incidência aos 30 dias (Tabela 1). Esses resultados são indicativos de que o progresso da mancha-anular do cafeeiro é totalmente dependente do inóculo proveniente das plantas infectadas, nas quais os ácaros se alimentam antes de chegar à lavoura, e não apenas das altas populações do ácaro.

Assim, se o ácaro chegar à lavoura inicialmente isento de partículas virais e as condições forem favoráveis para a sua reprodução, a sua prole poderá estar livre do vírus e não haverá ocorrência dos sintomas da mancha-anular. Os resultados obtidos no presente trabalho estão de acordo com os de Czermainski et al. (2007), para leprose (Citrus leprosis virus $C$ ) e B. phoenicis em citros, que mostraram forte correlação positiva entre a incidência da doença na primeira avaliação e em levantamentos posteriores, mas não entre a população do ácaro e a doença.

Como observado em citros (Czermainski et al., 2007), foi detectada a presença de B. phoenicis em todos os órgãos das plantas (folhas, ramos e frutos). $\mathrm{Na}$ Área 1, verificou-se maior número de ácaros nas folhas $(48,4 \%)$, em comparação aos ramos $(30,4 \%)$

Tabela 1. Correlação da incidência da mancha anular entre a primeira avaliação e aos 30,60 e 90 dias subsequentes.

\begin{tabular}{lcc}
\hline Área & Tempo (dias) & Incidência \\
\hline \multirow{2}{*}{1} & 30 & $0,57^{*}$ \\
& 60 & $0,14^{\mathrm{ns}}$ \\
2 & 90 & $0,34^{\mathrm{ns}}$ \\
\hline \multirow{2}{*}{} & 30 & $0,591^{*}$ \\
& 60 & $-0,30^{\mathrm{ns}}$ \\
& 90 & $-0,25^{\mathrm{ns}}$ \\
\hline
\end{tabular}

*Significativo a $5 \%$ de probabilidade. ${ }^{\text {ns }}$ Não significativo.

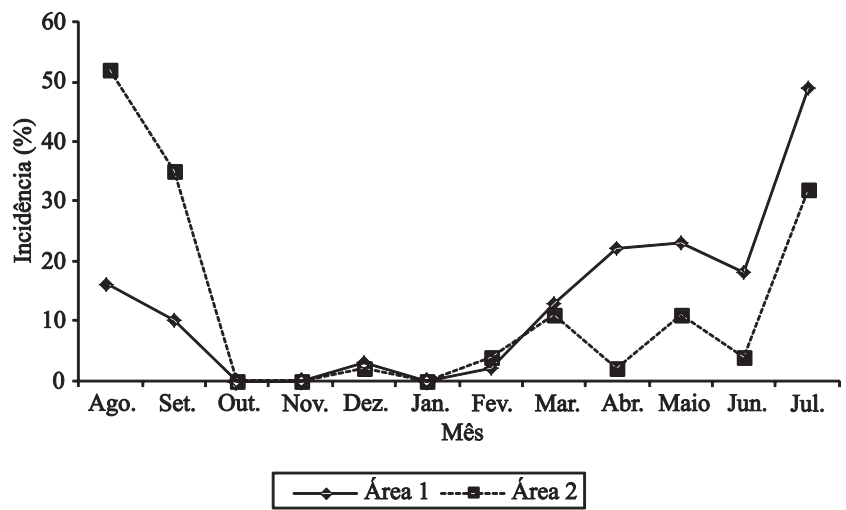

Figura 2. Incidência média da mancha anular do cafeeiro ao longo de 12 avaliações mensais em duas áreas experimentais de cafeeiro (Coffea arabica), em Coromandel, MG. 
e aos frutos (21,2\%) (Tabela 2). Houve maior número de ovos nos frutos (52, 9\%), seguidos pelas folhas e pelos ramos, que apresentaram 41,2 e $5,9 \%$ do total de ácaros encontrados, respectivamente. $\mathrm{Na}$ Área 2, a distribuição de ácaros foi diferente da observada na Área 1, com maiores percentagens nos ramos $(39,4 \%)$, seguido pelas folhas $(36.9 \%)$ e pelos frutos $(23,7 \%)$. O número de ovos foi sempre maior nos frutos $(48,8 \%)$, seguido pelos ramos $(37,8 \%)$ e pelas folhas $(13,4 \%)$. Os resultados da Área 1 estão de acordo com os de Reis \& Zacarias (2007). Esses resultados são contrários aos obtidos em citros, em que houve maior preferência do ácaro pelos frutos, seguidos pelos ramos e pelas folhas (Oliveira, 1986). $\mathrm{O}$ número total de ácaros observados nas duas áreas avaliadas foi maior que o número de ovos (Tabela 2). Esses resultados diferem dos verificados por Reis et al. (2000) que, ao avaliar a flutuação populacional deste ácaro no sul de Minas Gerais, constataram que a quantidade de ovos foi sempre superior à de ácaros. Uma possível explicação para esses resultados seria a diferença climática entre o sul de Minas e o Alto Paranaíba, no Município de Coromandel, MG, onde as temperaturas são sensivelmente mais elevadas, quando comparadas às dos municípios do sul do estado. Isso pode ter favorecido a maior ocorrência de ácaros

Tabela 2. Média geral da distribuição de ácaros adultos (Brevipalpus phoenicis) e ovos em folhas, ramos e frutos de plantas de cafeeiro (Coffea arabica) durante dois anos de avaliação em Coromandel, MG.

\begin{tabular}{llcccc}
\hline Área & Órgão & Ácaros & $(\%)$ & Ovos & $(\%)$ \\
\hline \multirow{3}{*}{1} & Folhas & 3,67 & 48,4 & 1,17 & 41,2 \\
& Ramos & 2,31 & 30,4 & 0,17 & 5,9 \\
& Frutos & 1,61 & 21,2 & 1,5 & 52,9 \\
\hline \multirow{2}{*}{2} & Folhas & 2,42 & 36,9 & 0,47 & 13,4 \\
& Ramos & 2,58 & 39,4 & 1,33 & 37,8 \\
& Frutos & 1,56 & 23,7 & 1,72 & 48,8 \\
\hline
\end{tabular}

adultos em comparação aos ovos, pois temperaturas mais elevadas aceleram o ciclo de B. phoenicis (Pedro Neto et al., 2010). Essa informação é importante para o controle químico do ácaro, pois o princípio ativo utilizado pode ter eficiência diferente como acaricida e ovicida (Celoto \& Papa, 2010).

$\mathrm{Na}$ Área 1, a incidência da mancha-anular, o número de ácaros nas folhas e nos ramos, e o número de ovos nos ramos não diferiram entre as parcelas tratadas com os dois acaricidas, mas foi significativamente inferior ao observado para a testemunha (Tabela 3). Contudo, o número de ácaros nos frutos foi significativamente menor apenas nas plantas tratadas com Dicofol 480 $\mathrm{EC}$, e os números de ovos nos ramos e nos frutos não apresentaram diferenças significativas entre os três tratamentos. Na Área 2, o número de ácaros nas folhas e nos ramos diminuiu significativamente nas plantas tratadas com Dicofol 480 EC, enquanto o tratamento com Cihexatina $500 \mathrm{SC}$ não diferiu da testemunha. O número de ácaros nos frutos e de ovos nos ramos foi igual nos três tratamentos; entretanto, o número de ovos nos dois tratamentos com acaricidas foi significativamente menor nas folhas e nos frutos, em comparação à testemunha.

A incidência da doença na Área 2 foi igual nos três tratamentos (Tabela 4), o que pode ser atribuído à desfolha que normalmente ocorre na planta infectada, pois a mancha-anular tende a se desenvolver na direção do pecíolo, o que causa a queda precoce da folha. Os maiores índices da doença ocorreram de agosto a setembro e de maio a julho, o que coincide com as épocas em que a população de ácaros foi maior (Figura 2). No entanto, para detectar as diferenças na incidência da mancha-anular do cafeeiro nas parcelas, as plantas deveriam ter sido vistoriadas praticamente todos os dias. Figueira (2008) observou que, após a visualização dos sintomas, a queda das folhas ocorreu

Tabela 3. Número médio de ácaros adultos (Brevipalpus phoenicis) e ovos em folhas, ramos e frutos de plantas de cafeeiro (Coffea arabica) tratadas com acaricidas durante dois anos de avaliação ${ }^{(1)}$.

\begin{tabular}{|c|c|c|c|c|c|c|c|c|c|c|c|c|}
\hline \multirow[t]{3}{*}{ Tratamento } & \multicolumn{6}{|c|}{ Área 1} & \multicolumn{6}{|c|}{ Área 2} \\
\hline & \multicolumn{2}{|c|}{ Folhas } & \multicolumn{2}{|c|}{ Ramos } & \multicolumn{2}{|c|}{ Frutos } & \multicolumn{2}{|c|}{ Folhas } & \multicolumn{2}{|c|}{ Ramos } & \multicolumn{2}{|c|}{ Frutos } \\
\hline & Ácaro & Ovos & Ácaro & Ovos & Ácaro & Ovos & Ácaro & Ovos & Ácaro & Ovos & Ácaro & Ovos \\
\hline Dicofol 480 EC & $3,62 \mathrm{a}$ & $2,18 \mathrm{a}$ & $3,88 \mathrm{a}$ & $2,46 a$ & $2,58 \mathrm{a}$ & $2,25 \mathrm{a}$ & $3,14 \mathrm{a}$ & $2,19 a$ & $3,12 \mathrm{a}$ & $2,27 \mathrm{a}$ & $1,88 \mathrm{a}$ & $1,77 \mathrm{a}$ \\
\hline Cihexatina $500 \mathrm{SC}$ & $4,21 \mathrm{a}$ & $2,50 \mathrm{a}$ & $4,25 \mathrm{a}$ & $3,15 \mathrm{a}$ & $3,54 b$ & $3,29 a$ & $4,90 b$ & $2,61 \mathrm{a}$ & $5,00 \mathrm{~b}$ & $3,14 \mathrm{a}$ & $2,41 \mathrm{a}$ & $2,40 \mathrm{a}$ \\
\hline Testemunha & $8,35 b$ & $4,40 \mathrm{~b}$ & $6,68 b$ & $2,82 \mathrm{a}$ & $4,41 \mathrm{~b}$ & $4,27 \mathrm{a}$ & $6,85 b$ & $4,14 b$ & $7,09 \mathrm{~b}$ & $4,79 \mathrm{a}$ & $4,28 \mathrm{a}$ & $4,53 b$ \\
\hline $\mathrm{CV}(\%)$ & 11,41 & 21,58 & 14,19 & 29,49 & 16,46 & 20,77 & 15,33 & 15,00 & 15,35 & 22,57 & 33,56 & 27,55 \\
\hline
\end{tabular}

${ }^{(1)}$ Médias seguidas de letras iguais, nas colunas, não diferem pelo teste de Scott Knott, a 5\% de probabilidade. 
Tabela 4. Incidência média da mancha anular em folhas de cafeeiro (Coffea arabica), cultivar Catuaí-Vermelho, durante o segundo ano de avaliação, em duas áreas experimentais, em Coromandel, $\mathrm{MG}^{(1)}$.

\begin{tabular}{lcc}
\hline Tratamento & Área 1 & Área 2 \\
\hline Dicofol 480 EC & $2,96 \mathrm{a}$ & $5,74 \mathrm{a}$ \\
Cihexatina 500 SC & $3,79 \mathrm{a}$ & $12,87 \mathrm{a}$ \\
Testemunha & $12,96 \mathrm{~b}$ & $8,05 \mathrm{a}$ \\
\hline CV $(\%)$ & 11,19 & 8,99 \\
\hline
\end{tabular}

${ }^{(1)}$ Médias seguidas de letras iguais, nas colunas, não diferem pelo teste de Scott Knott, a 5\% de probabilidade.

no período de quatro a cinco semanas, mas que pode ser acelerada em temperaturas mais elevadas.

Uma vez que a utilização de acaricidas diminui a população do vetor, o seu uso deverá contribuir para o controle da mancha-anular. Porém, a aplicação do defensivo a partir do momento em que for detectada a presença da doença no campo não impedirá a desfolha, que ocorrerá após a alimentação do ácaro virulífero na planta. A severidade da doença dependerá da quantidade de ácaros infectados que chegam à lavoura, ou seja, do potencial de inóculo. Portanto, para evitar a desfolha causada pela doença, o tratamento com acaricidas deve ser preventivo, para impedir o estabelecimento da população de ácaros virulíferos na lavoura. Se isso não for possível, é importante eliminar a população de ácaros contaminados, o que não impede a desfolha, mas evita que esses ácaros tornem-se fonte de inóculo para a estação seguinte, para essa e outras lavouras vizinhas, quando ocorrerão novas desfolhas em razão das novas infecções virais.

Segundo Reis \& Zacarias (2007), o controle deve ser realizado por meio de duas aplicações direcionadas ao terço inferior e interno da planta, com a primeira aplicação realizada logo após a colheita. Como nesse período as plantas de café ficam mais arejadas, ocorre maior penetração do produto na planta. Uma segunda aplicação deve ser realizada no estádio de chumbinho, quando a formação dos frutos começa, época em que os ácaros realizam oviposições neste órgão, especificamente na região da coroa.

\section{Conclusões}

1. Os maiores índices populacionais do ácaro ocorrem de março a setembro e coincidem com as maiores incidências da mancha-anular do cafeeiro.
2. O progresso da mancha-anular do cafeeiro é dependente do inóculo presente anteriormente na folha e não apenas das altas populações do ácaro.

3. Há maior preferência do ácaro, na sua fase adulta, por folhas, além de maior oviposição nos frutos.

4. Observa-se menor taxa do progresso da doença nas lavouras tratadas com acaricidas, o que indica sua eficiência no controle do ácaro.

\section{Agradecimentos}

Ao Programa Nacional de Pesquisa e Desenvolvimento do Café da Embrapa, ao Conselho Nacional de Pesquisa e Desenvolvimento Científico e Tecnológico, à Coordenação de Aperfeiçoamento de Pessoal de Nível Superior e à Fundação de Amparo à Pesquisa do Estado de Minas Gerais, pelo apoio.

\section{Referências}

BITTANCOURT, A.A. A mancha anular, uma nova ameaça do cafeeiro. O Biológico, v.4, p.404-405, 1938. Notas e informações.

BOARI, A. de J.; FIGUEIRA, A. dos R.; NEDER, D.G.; SANTOS, R. de C.; GUSSIM, M.M.; NOGUEIRA, N.L.; ROSSI, M.L. Vírus da mancha anular do cafeeiro (Coffee ringspot virus - CoRSV): influência na qualidade da bebida e na produção de grãos de café. Summa Phytopathologica, v.32, p.192-194, 2006.

CELOTO, F.J.; PAPA, G. Atividade do acaricida etoxazol sobre a mortalidade e reprodução do ácaro-da-leprose Brevipalpus phoenicis (Geijskes) (Acari: Tenuipalpidae), em citros. Revista Brasileira Fruticultura, v.32, p.1038-1043, 2010.

CHAGAS, C.M. Associação do ácaro Brevipalpus phoenicis (Geijskes) à mancha anular do cafeeiro. O Biológico, v.39, p.229-232, 1973.

CHAGAS, C.M. Mancha anular do cafeeiro: transmissibilidade, identificação do vetor e aspectos anatomo-patológicos da espécie Coffea arabica L. afetada pela moléstia. 1978. 132p. Tese (Doutorado) - Universidade de São Paulo, São Paulo.

COMPANHIA NACIONAL DO ABASTECIMENTO. Acompanhamento da safra brasileira: safra de café 2011/2012: primeirolevantamento: março de 2012. Disponível em: $<$ http://www. conab.gov.br/OlalaCMS/uploads/arquivos/11_01_06_08_52_41_ boletim_cafe_1a_estimativa_safra_2011.pdf $>$. Acesso em: $0 \overline{8}$ maio 2012 .

CZERMAINSKI, A.B.C.; BASSANEZI, R.B.; LARANJEIRA, F.F.; AMORIM, L. Dinâmica temporal da população do ácaro Brevipalpus phoenicis e da leprose dos citros sob condições naturais de epidemia. Fitopatologia Brasileira, v.32, p.295-303, 2007.

FERNANDES, A.P.; FERREIRA, M. da C.; OLIVEIRA, C.A.L. de. Eficiência de diferentes ramais de pulverização e volumes de calda no controle de Brevipalpus phoenicis na cultura do café. Revista Brasileira de Entomologia, v.54, p.130-135, 2010. 
FERREIRA, D.F. SISVAR: um programa para análises e ensino de estatística. Revista Symposium, v.6, p.36-41, 2008.

FIGUEIRA, A.R. A mancha anelar do cafeeiro causada pelo Coffee ringspot vírus (CoRSV) em Minas Gerais. In: FERNANDES, L.H.M. (Org.). Manejo fitossanitário da cultura do cafeeiro. Brasília: Sociedade Brasileira de Fitopatologia, 2008. p.127-139.

FRANCO, R.A.; REIS, P.R.; ZACARIAS, M.S.; ALTOÉ, B.F.; PEDRO NETO, M. Dinâmica populacional de Oligonychus ilicis (McGregor, 1917) (Acari: Tetranychidae) em cafeeiro e de fitoseídeos associados a ele. Coffee Science, v.3, p.38-46, 2008.

HARISSON, B.D. Epidemiology of plant virus diseases. In: PLUMB, R.T.; THRESH, J.M. (Ed.). Plant virus epidemiology: the spread and control of insect-borne viruses. Oxford: Blackwell Scientific, 1983. p.1-6

JEGER, M.J.; MADDEN, L.V.; BOSCH, F.V. The effect of transmission route on plant virus epidemic development and disease control. Journal of Theoretical Biology, v.258, p.198-207, 2009.

KITAJIMA, E.E.; COSTA, A.S. Partículas baciliformes associadas à mancha anular do cafeeiro. Ciência e Cultura, v.24, p.542-545, 1972.

MADDEN L.V.; HUGHES, G.; BOSCH, F. van den. The study of plant disease epidemics. Saint Paul: APS, 2007. 421p.

MORI, A.E. Efeito de acaricidas na população do ácaro Brevipalpus phoenicis Geijskes e a incidência da mancha-anular causada pelo Coffee ringspot vírus (CoRSV). 2003. 71p. Dissertação (Mestrado) - Universidade Federal de Lavras, Lavras.

OLIVEIRA, C.A.L. de. Flutuação populacional e medidas de controle do ácaro da leprose Brevipalpus phoenicis (Geijskes, 1939) em citros. Laranja, v.1, p.1-31, 1986.

PEDRO NETO, M.; REIS, P.R.; ZACARIAS, M.S.; SILVA, R.A. Influence of rainfall on mite distribution in organic and conventional coffee systems. Coffee Science, v.5, p.67-74, 2010.
REIS, P.R.; CHAGAS, S.J. de R. Relação entre o ataque do ácaro-plano e da mancha-anular com indicadores da qualidade do café. Ciência e Agrotecnologia, v.25, p.72-76, 2001.

REIS, P.R.; CHIAVEGATO, L.G.; MORAES, G.J.; ALVES, E.B.; SOUZA, E.O. Seletividade de agroquímicos ao ácaro predador Iphiseiodes zuluagai Denmark \& Muma (Acari: Phytoseiidae). Anais da Sociedade Entomológica do Brasil, v.27, p.265-274, 1998.

REIS, P.R.; PEDRO NETO, M.; FRANCO, R.A. Controle de Brevipalpus phoenicis (Geijskes, 1939) e Oligonychus ilicis (McGregor, 1917) (Acari: Tenuipalpidae, Tetranychidae) em cafeeiro e o impacto sobre ácaros benéficos. II - Spirodiclofen e Azocyclotin. Ciência e Agrotecnologia, v.29, p.528-537, 2005.

REIS, P.R.; SOUSA, E.O.; ALVES, E.B. Seletividade de produtos fitossanitários ao ácaro predador Euseius alatus DeLeon (Acari: Phytoseiidae). Revista Brasileira de Fruticultura, v.21, p.350-355, 1999.

REIS, P.R.; SOUZA, J.C. de; SANTACECÍLIA, L.V.C.; SILVA, R.A.; ZACARIAS, M.S. Manejo integrado das pragas do cafeeiro. In: REIS, P.R.; CUNHA, R.L. da (Ed.). Café arábica: do plantio à colheita. Lavras: Epamig, 2010. p.573-688.

REIS, P.R.; SOUZA, J.C. de; SOUSA, E.O. de; TEODORO, A.V. Distribuição espacial do ácaro Brevipalpus phoenicis (Geijskes) (Acari: Tenuipalpidae) em cafeeiro (Coffea arabica L.). Anais da Sociedade Entomológica do Brasil, v.29, p.177-183, 2000.

REIS, P.R.; ZACARIAS, M.S. Ácaros em cafeeiro. Belo Horizonte: Epamig, 2007. 76p. (Epamig. Boletim técnico, 81).

REIS, P.R.; ZACARIAS, M.S.; SILVA, R.A.; MARAFELI, P.P. Manejo de ácaros em cafeeiro. In: FERNANDES, L.H.M. (Org.). Manejo fitossanitário da cultura do cafeeiro. Brasília: Sociedade Brasileira de Fitopatologia, 2008. p.173-184.

SAS INSTITUTE. SAS/STAT: user's Guide. Version 9.2. Cary: SAS Institute, 2009. 7869p.

Recebido em 28 de novembro de 2011 e aprovado em 6 de junho de 2012 